\title{
FORMULATION AND OPTIMIZATION OF ITRACONAZOLE PRONIOSOMES USING BOX BEHNKEN DESIGN
}

\author{
AHMED M. SAMY1, AFAF A. RAMADAN², AMAL S. M. ABU EL-ENIN², YASMIN I. M. MORTAGI³ \\ 1,2Department of Pharmaceutics and Industrial Pharmacy, Faculty of Pharmacy, Al-Azhar University, Nasr City, Cairo, Egypt, ${ }^{3}$ Faculty of \\ Pharmacy and Pharmaceutical Industries, Sinai University, El Arish, North Sinai, Egypt \\ Email: yasmin.mohamed@su.edu.eg \\ Received: 30 Oct 2017, Revised and Accepted: 09 Jan 2018
}

ABSTRACT

Objective: The aim of the present study was to obtain an optimized formula of itraconazole (ITC) proniosomes using Box Behnken design.

Methods: Itraconazole proniosomes were prepared using span 60 and/or brij 35 as surfactants, cholesterol and lecithin as a penetration enhancer by slurry method. Various trials have been carried out for investigation of proniosomes. Parameters such as entrapment efficiency (EE\%), in vitro drug release, zeta potential, vesicle size and Transmission Electron Microscope were assessed for evaluation of proniosomes.

Results: Entrapment efficiency (EE\%) was found to be between $78.56 \%$ and $95.46 \%$. The release profile of itraconazole proniosomes occurred in two distinct phases, an initial phase for about $8 \mathrm{~h}$, followed by a slow phase for $16 \mathrm{~h}$. The release pattern shown by these formulations was Higuchi diffusion controlled mechanism. The zeta potential values for all itraconazole proniosomes were in the range of- 21.71 to-34.53 mV which confirms their stability. All itraconazoleproniosomes formula was found to be nano-sized and were appeared to be spherical in shape with sharp boundaries. One way analysis of variance (ANOVA) study showed that HLB $\left(\mathrm{X}_{1}\right)$ had the main effects on most responses (Y).

Conclusion: Box behnken design facilitates optimization of the formulation ingredients on entrapment efficiency, in vitro release of itraconazole proniosomes, zeta potential and vesicle size. Finally, an optimum level of factors was provided by the optimization process.

Keywords: Box behnken design, Proniosomes, Entrapment efficiency (EE\%), Itraconazole (ITC), Optimization

(C) 2018 The Authors. Published by Innovare Academic Sciences Pvt Ltd. This is an open access article under the CC BY license (http://creativecommons.org/licenses/by/4.0/) DOI: http://dx.doi.org/10.22159/ijap.2018v10i2.23382

\section{INTRODUCTION}

In recent years, considerable attention has been focused on the development of a new drug delivery system (NNDS). Among them vesicular particulate carrier is of much importance. Various type vesicular particulate drug delivery systems include liposomes, niosomes, transferosomes, ethosomes and cubosomes [1]. Niosomes have been evaluated in many pharmaceutical applications due to their important advantages to reduce the systemic toxicity by encapsulation of treatment agents and show slow drug release [2]. The approaches like provesicular drug delivery like proniosomes have also been developed which have better stabilities in comparison to simple vesicular drug delivery systems. Proniosomes were developed as a promising drug delivery system to counteract the stability problems associated with niosomes (degradation by hydrolysis or oxidation and sedimentation, aggregation, or fusion during storage) [3]. Proniosomes are dry, free-flowing and granular products which upon addition of water, disperses or dissolves to form a multilamellar noisome suspension suitable for administration by oral or other routes. Itraconazole (ITC) is a broad spectrum antifungal agent and belongs to triazole group that can be indicated for the treatment of local and systemic fungal infections [4]. Itraconazole is weakly basic ( $\mathrm{pk}_{\mathrm{a}} 3.7$ ) and highly hydrophobic. The mechanism of action of itraconazole is impairing the synthesis of ergosterol, an essential component of the fungal cell membrane [5]. Optimization is the search for a result that is the best possible within a limited field of search, so the type and components of a formulation can be selected according to previous experience [6]. In the present study, an attempt was made to develop, optimize and evaluate itraconazole proniosomes using selected surfactants and studying theirs in vitro properties.

\section{MATERIALS AND METHODS}

\section{Materials}

Itraconazole (ITC), span 60, brij 35, cholesterol and mannitol was purchased from Sigma Chemical Company, (USA), soya lecithin phospholipon $90 \mathrm{H}$ was kindly donated by Lipoid (Lipoid, Germany), methanol, chloroform, sodium hydroxide, potassium dihydrogenortho phosphate were purchased from El-Nasr Chemical Company, (Cairo, Egypt). All other chemicals used were of analytical grade.

\section{Methods}

\section{Preparation of itraconazoleproniosomes}

Proniosomes were prepared by the slurry method using three variables include HLB $\left(\mathrm{X}_{1}\right)$, a surfactant to cholesterol ratio $\left(\mathrm{X}_{2}\right)$ and a ratio of lecithin $\left(\mathrm{X}_{3}\right)$. These variables were studied with a fifteen box behnken design [Statgraphics ${ }^{\circledR}$ plus (version 4), Manugistics Inc., Rockville, MD, USA) software]. Mixed span 60 [HLB 4.7] and brij 35 [HLB 17] surfactants were used in different HLB values which were calculated according to the equation:

$$
\% \text { brij } 35=\left[\text { RHLB-HLB }{ }_{\text {low }}\right] /\left[\mathrm{HLB}_{\text {high }}-\mathrm{HLB}_{\text {low }}\right] .
$$

The required weight of a surfactant (span-60 and/or brij 35), cholesterol and drug was dissolved in chloroform: methanol (1:1) solution then was poured in a $100 \mathrm{ml}$ round bottom flask containing mannitol as a carrier. The flask was attached to a rotary evaporator [Buchi Rotavapor R-3000, (Switzerland)] to remove solvent at 60 rpm, using a temperature of $45^{\circ} \mathrm{C} \pm 2$, and a reduced pressure of 600 $\mathrm{mmHg}$ until the mass in the flask had become a dry product. The obtained proniosomes were further dried overnight in a desiccator at room temperature [7]

\section{Micromeritics properties of proniosomes' powders}

The flow properties of itraconazole proniosomes are vital in handling and processing operations. The flow properties were studied through measuring the Angle of repose, Carr's compressibility index and Hausner's ratio. The angle of repose was determined by using conventional fixed funnel method. The Carr's compressibility index and Hausner's ratio were calculated from the bulk and tapped density of the proniosomes powders [1].

$\mathrm{D}_{\mathrm{b}}=\mathrm{Wt} /$ bulk volume $=\mathrm{W} / \mathrm{V}_{\mathrm{b}}$

$\mathrm{D}_{\mathrm{t}}=\mathrm{Wt} / \mathrm{tap}$ volume $=\mathrm{W} / \mathrm{V}_{\mathrm{t}}$ 
Hausner ratio $=\mathrm{D}_{\mathrm{t} / \mathrm{D}} \mathrm{D}_{\mathrm{b}}$

Compressibility $\%=\left(D_{t}-D_{b} / D_{t}\right) \times 100$

Angle of repose Tan $\theta=h / r$

\section{Entrapment efficiency of itraconazole proniosomes}

Hydrated itraconazole proniosomal dispersions were allowed to sediment using a centrifuge at $15000 \mathrm{rpm}$ for $45 \mathrm{~min}$. The supernatant liquid was separated, diluted to $100 \mathrm{ml}$ with phosphate buffer $\mathrm{pH}$ 7.4, filtered using a membrane filter $(0.45 \mu \mathrm{m}$ pore size), and measured using a UV spectrophotometer [Model UV-1601PC Shimadzu, Japan] at a predetermined wavelength of $262.5 \mathrm{~nm}$ which was in good agreement with [Sampathi et al., 2015] [8]. The entrapment efficiency of itraconazole was calculated as follows:

$$
\text { Entrapment efficiency }(\%)=\frac{\text { (Total amount of drug-amount of un-entrapped drug) }}{\text { (Total amount of drug) }} \text { X } 100
$$

\section{In vitro release of itraconazole}

This study was carried out using a USP dissolution tester [Dissolution apparatus, Erweka $\mathrm{GmbH}$, Germany]. Itraconazole niosomal dispersion (equivalent to $5 \mathrm{mg}$ drug) was transferred to cylindrical tubes $(2.5 \mathrm{~cm}$ in diameter and $6 \mathrm{~cm}$ in length). Each tube was tightly covered with a molecular porous membrane from one end and attached to the shafts of the USP Dissolution apparatus from the other end. The shafts were then lowered to the vessels containing $250 \mathrm{ml}$ of phosphate buffer $(\mathrm{pH} 7.4)$ at $37 \pm 0.5{ }^{\circ} \mathrm{C}$, and $100 \mathrm{rpm}$. Five $\mathrm{ml}$ samples were withdrawn at time intervals of 1,2 , $3,4,6,8,12$, and $24 \mathrm{~h}$ followed by replacement with fresh medium. The samples were analyzed spectrophotometrically at $262.5 \mathrm{~nm}$. The obtained data were subjected to kinetic treatment, according to zero, first, and Higuchi diffusion models [9]. The correlation coefficient ( $\mathrm{r}$ ) was determined in each case.

\section{Zeta potential determination}

Particle sizing systems were used in the determination of zeta potential of all formulations. The formulations were hydrated with distilled water and then converted to niosomes; the formed niosomes were used to determine the zeta potential by using Particle Sizing System, Inc. Santa Barbara [10].

\section{Vesicle size analysis}

This is performed for characterization of vesicle's size. The proniosomal powders were hydrated with phosphate buffer $\mathrm{pH}$ 7.4) and subjected to bath sonication for $1 \mathrm{~min}$ and the resulting dispersion was used for the determination of size. Vesicle sizes of niosomes were determined by using Particle Sizing System, Inc. Santa Barbara [1].

\section{Statistical analysis}

The significance of estimation was determined by ANOVA followed by Student's test.

\section{Optimization of the formulation ingredients}

Box behnken design is independent quadratic design in that it doesn't contain an embedded factorial design. In this design, the treatment combinations are at the midpoints of the edges of the process space. These designs are rotatable and require 3 levels of each factor, thus helping in optimizing a process using a small number of experimental runs [11]. The model constructed was as follows; $\mathrm{Y}=$ $\mathrm{a}_{0}+\mathrm{a}_{1} \mathrm{X}_{1}+\mathrm{a}_{2} \mathrm{X}_{2}+\mathrm{a}_{3} \mathrm{X}_{3}+\mathrm{a}_{4} \mathrm{X}_{1} \mathrm{X}_{2}+\mathrm{a}_{5} \mathrm{X}_{2} \mathrm{X}_{3}+\mathrm{a}_{6} \mathrm{X}_{1} \mathrm{X}_{3}+\mathrm{a}_{7} \mathrm{X}_{1}{ }^{2}+\mathrm{a}_{8} \mathrm{X}_{2}{ }^{2}+\mathrm{a}_{9} \mathrm{X}_{3}{ }^{2}$

$-+E$. Where ao to a9 are the regression coefficient, $X_{1}, X_{2}$ and $X_{3}$ are the factors studied, $Y$ is the measured response associated with each factor level combination and $\mathrm{E}$ is the error term. Optimization was performed to obtain the levels of $X_{1}, X_{2}$ and $X_{3}$, which give optimum values of $Y_{1}, Y_{2}, Y_{3}$ and $Y_{4}$ at constrained conditions.

\section{Formulation of the optimized formula}

The preparation, entrapment efficiency, in vitro release, the kinetic study, zeta potential determination and vesicle size (as described before) of the optimized formula were studied and the optimized formula was then characterized by transmission electron eicroscope
[TEM Jeol-200 CX, Japan] and scanning electron microscope [SEM, S4100, Hitachi, Japan].

\section{RESULTS AND DISCUSSION}

\section{Preparation of itraconazole proniosomes}

Three different variables include: $\operatorname{HLB}\left(\mathrm{X}_{1}\right)$, a surfactant to cholesterol ratio $\left(\mathrm{X}_{2}\right)$ and a ratio of lecithin $\left(\mathrm{X}_{3}\right)$ as shown in the table (1) were screened using box behnken design and fifteen different formulae of itraconazole proniosomes were obtained as shown in the table (2). In this perspective, proniosome approach has resolved many stability issues pertaining to aqueous noisome dispersions. (HLB) is a good indicator of the vesicle-forming ability of any surfactant. With the Sorbitan surfactants (span), an HLB number of between 4 and 8 was found to be compatible with vesicle formation [12]. The morphology and stability of the niosomes are mainly dependent on the concentration of nonionic surfactant and cholesterol and any alteration in their composition leads to disruption of vesicles, which leads to leakage of the free drug before the drug diffusion and fusion of vesicles with the gastrointestinal membrane. A parameter like the ratio of lecithin is a good indicator of membrane stabilization.

\section{Micromeritics properties of proniosomes' powders}

Our results indicated the small angle of repose of prepared itraconazole proniosomes ranged from $12.4^{\circ}$ for F13 to $21^{\circ}$ for F7 assuring excellent flow properties. In addition to the angle of repose, Carr's index showed a maximum value of $17.5 \%$ and the minimum one of $8.4 \%$ and Hausner's ratio were also less than 1.25 ensuring an acceptable flow for proniosomes powder formulations. These results were in good agreement with Fayed et al., [2016] who estimated the Carr's index of permeation proniosomes preparations which showed good flowability [13].

\section{Entrapment efficiency of itraconazole proniosomes}

The range of the entrapment efficiency of the prepared proniosomes was found to be between $78.56 \%$ for F6 and $95.46 \%$ for F13 as shown in fig. (1). Fig. (2: A-H) showed the effect of the different independent variables on the entrapment efficiency of itraconazole using STRATIGRAPHIC plus computer program. By increasing $\left(\mathrm{X}_{1}\right)$; entrapment efficiency decreased from 94.43 to $85.48 \%$, while by increasing $\left(\mathrm{X}_{2}\right)$; entrapment efficiency, increased from 87.31 to $92.79 \%$ and by increasing $\left(\mathrm{X}_{3}\right)$; entrapment efficiency increased from 85.15 to $89.16 \%$. This could be explained on the basis that the vesicle formation ability of hydrophobic non-ionic surfactants could be understood as the molecule geometry fulfilled a proper critical packing parameter where the highly lipophilic drug is expected to be housed almost completely within the vesicles bilayer [14]. Another possible explanation of these findings is related to the ability of cholesterol to be intercalated into the bilayers, thereby preventing the leakage of the drug through the bilayers. Moreover, the addition of lecithin increased the system stability due to the high transition temperature of hydrogenated lecithin $\left(48{ }^{\circ} \mathrm{C}\right)$ and its unique advantage over unhydrogenated one in enhancing the rigidifying effect of cholesterol and formation of less leaky membrane bilayers [15].

Our results were inconsistent with Acharya et al., [2016] who showed the highest entrapment efficiency of candesartan cilexetil proniosomes when using span 60 due to its ability to entrap the drug because of longer saturated alkyl chain which lower HLB value. Also, the highest entrapment efficiency was shown in a formulation containing span 60: cholesterol in ratio 2:1. The reason for that was as cholesterol content of the formulation was increased, entrapment efficiency of the drug was also increased. As the use of cholesterol in the proniosomal formulations not only improves the fluidity but also improves the stability of the bilayer membrane because entrapment efficiency of niosome was governed by the ability of the formulation to retain drug molecules in the bilayer membrane of the vesicles. This characteristic of cholesterol decreases leakage of the drug molecule from the bilayer structure and also provides a spherical smooth surface to the bilayer vesicles. However, a further increase in cholesterol level lowers the drug entrapment efficiency of bilayer vesicles formulation. This could be due to the fact that the cholesterol beyond a certain level starts disrupting the regular bilayer structure of vesicles leading to loss of drug entrapment [16]. 
Table 1: Formulation factors in Box behnken design

\begin{tabular}{|c|c|c|}
\hline Independent factors & Low & High \\
\hline $\mathrm{X}_{1}=\mathrm{HLB}$ & 4.7 & 17 \\
\hline $\mathrm{X}_{2}=$ Surfactant to cholesterol ratio & $1: 1$ & $2: 1$ \\
\hline $\mathrm{X}_{3}=$ Ratio of lecithin & 0 & 1 \\
\hline
\end{tabular}

Table 2: The designed formulae of itraconazole proniosomes

\begin{tabular}{|c|c|c|c|}
\hline Formula No. & $\mathbf{X}_{1}$ & $\mathbf{X}_{2}$ & $\mathbf{X}_{3}$ \\
\hline F1 & 10.85 & $1: 1$ & 1 \\
\hline $\mathrm{F} 2$ & 10.85 & $1: 1$ & 0 \\
\hline F3 & 17 & $1: 1$ & 0.5 \\
\hline F4 & 17 & $2: 1$ & 0.5 \\
\hline F5 & 10.85 & $1.5: 1$ & 0.5 \\
\hline F6 & 17 & $1.5: 1$ & 0 \\
\hline F7 & 4.7 & $1: 1$ & 0.5 \\
\hline F8 & 10.85 & $2: 1$ & 0 \\
\hline F9 & 10.85 & $1.5: 1$ & 0.5 \\
\hline F10 & 4.7 & $1.5: 1$ & 0 \\
\hline F11 & 4.7 & $2: 1$ & 0.5 \\
\hline F12 & 10.85 & $1.5: 1$ & 0.5 \\
\hline F13 & 4.7 & $1.5: 1$ & 1 \\
\hline F14 & 10.85 & $2: 1$ & 1 \\
\hline F15 & 17 & $1.5: 1$ & 1 \\
\hline
\end{tabular}

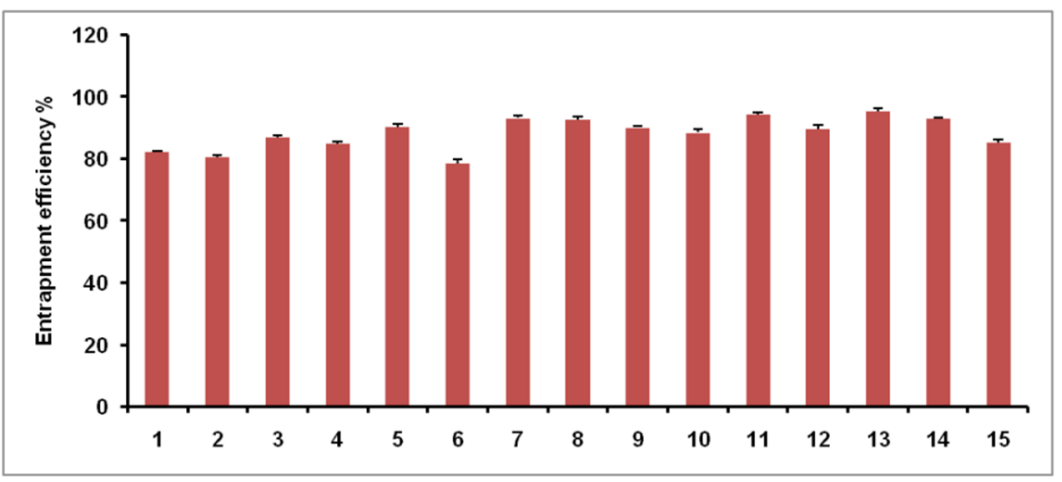

Fig. 1: Entrapment efficiency of itraconazole proniosomes, data's are expressed as mean $\pm S D(n=3)$

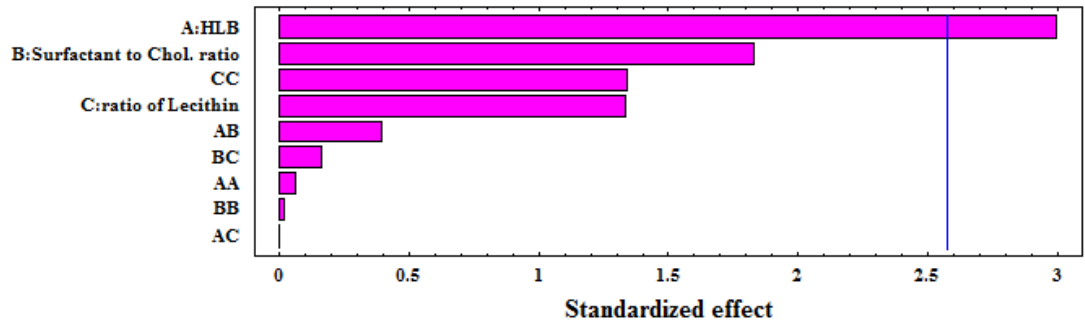

Fig. 2: [A] Standardized pareto chart for entrapment efficiency

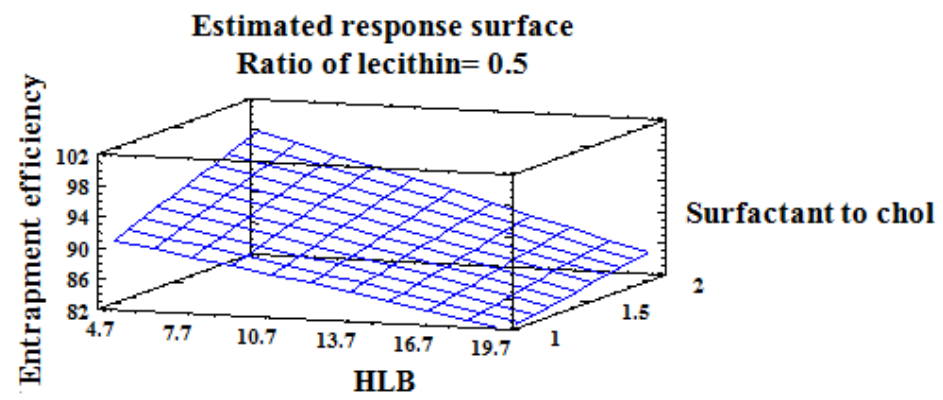

Fig. 2: [B] Three-dimensional contour plot for the effect of $X_{1}$ and $X_{2}$ on entrapment efficiency of itraconazole proniosomes 


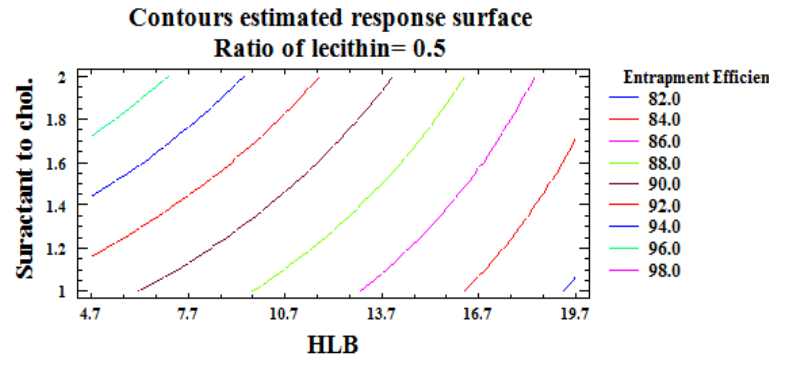

Fig. 2: [C] Two-dimensional contour plot for the effect of $X_{1}$ and $\mathrm{X}_{2}$ on entrapment efficiency of itraconazole proniosomes

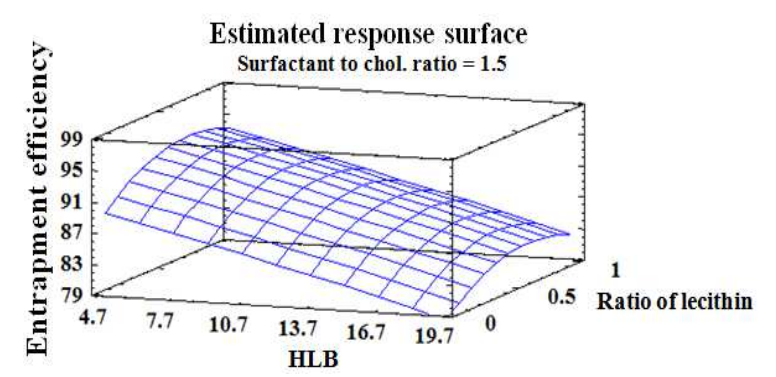

Fig. 2: [D] Three-dimensional contour plot for the effect of $X_{1}$ and $X_{3}$ on entrapment efficiency of itraconazole proniosomes

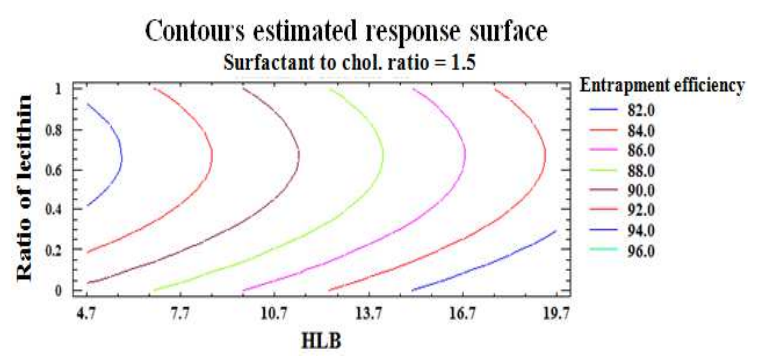

Fig. 2: [E] Two-dimensional contour plot for the effect of $X_{1}$ and $X_{3}$ on entrapment efficiency of itraconazole proniosomes

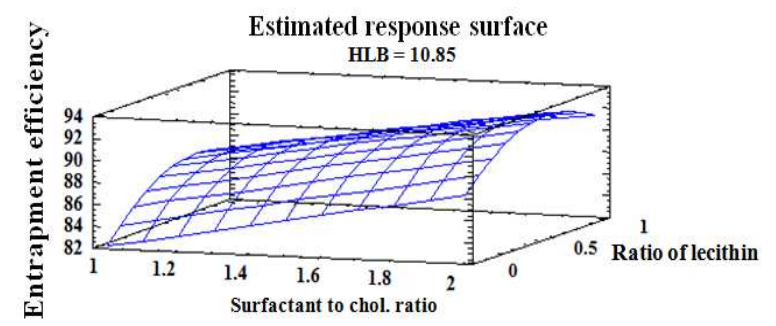

Fig. 2: [F] Three-dimensional contour plot for the effect of $X_{2}$ and $\mathrm{X}_{3}$ on entrapment efficiency of itraconazole proniosomes

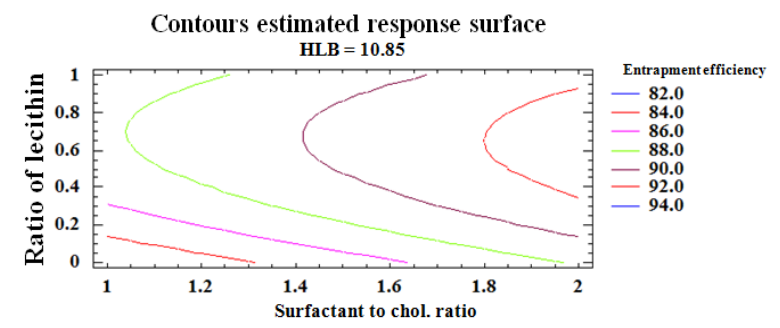

Fig. 2: [G] Two-dimensional contour plot for the effect of $X_{2}$ and $\mathrm{X}_{3}$ on entrapment efficiency of itraconazole proniosomes

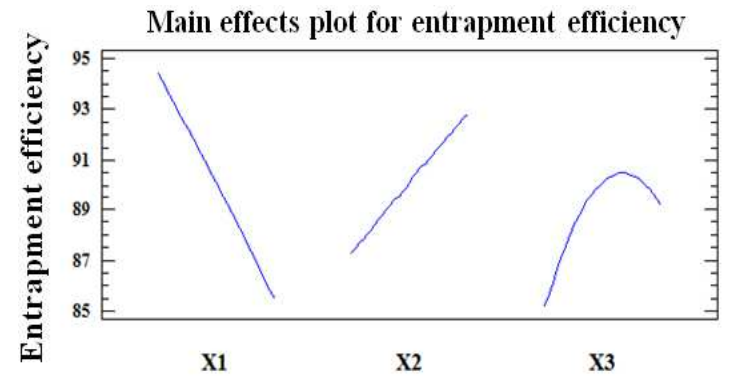

Fig. 2: [H] Main effect plot showing the effect of $X_{1}, X_{2}$ and $X_{3}$ On $Y_{1}$

\section{In vitro release of itraconazole}

Fig. (3-5) showed the release profiles of from the prepared niosomes which were occurring in two distinct phases, an initial phase in which rapid drug leakage was observed and stayed for about $8 \mathrm{~h}$, followed by slow phase continued for $16 \mathrm{~h}$. The initial phase was due to desorption of the drug from the surface of niosomes while the drug release in the slow phase was regulated by diffusion through the swollen niosomal bilayers and breakage of polymers [17]. This was inconsistent with Abdelbary et al., [2017] who found that the release profiles of ketoconazole from the different prepared proniosomal gel formulae were found to be biphasic release, A rapid drug leakage was observed in the initial phase, where about 25-55 $\%$ of the entrapped drug was released within the first few hours, while in the second phase, a slow release of the drug was observed from the different proniosomal formulations [18]. But, this was not inconsistent with Kumar et al., [2017] who found that the release of Cefixime from niosomal suspension occurred slowly and later immediate release due to penetration enhancement of nonionic surfactant [19].

From fig. (6: A-H), it was concluded that; the rate of release was decreased as $\left(\mathrm{X}_{1}\right)$ increased. Although the general features of the release profile of the proniosomes derived niosomes prepared using conventional surfactants revealed significant increase $(p<0.01)$ in the percentage drug released with the increase in HLB since hydrophilic surfactants have higher solubilizing power on hydrophobic solutes in aqueous medium compared to hydrophobic surfactants but presence of cholesterol and lecithin resulted in a more intact lipid bilayer which acts as a barrier for drug release, so decreased its leakage and permeability, hindered the release of entrapped drug from the vesicles and led to a significant slow release profile [15]. Also, the presence of double bonds in phosphatidylcholine allow the chain bend (undergo conformational rotation to give cis/transforms); so the adjacent molecule was not tightly close enough, when they assemble with non-ionic surfactants, lead to the formation of the more permeable bilayer. If the saturation of double bond occurs, it forces the bilayer molecules to get arranged to form a less permeable bilayer.

The rate of release was increased with increasing $\left(\mathrm{X}_{2}\right)$. This could be due to the emulsification effect of the surfactant after the hydration of the noisome by the dissolution medium [20]. The release rate of itraconazole niosomes was increased till ratio of lecithin become 0.5 then decreased; this was because of factors that stabilize the vesicle membrane and increase the entrapment efficiency of a hydrophobic drug as itraconazole will slow down the release profile [15].

As shown in the table (3) the best kinetic order for the in vitro release of itraconazole was calculated from the highest values of the obtained correlation coefficients. The kinetic analysis of all release profiles followed diffusion controlled mechanism. Our results were in good agreement with Arafa et al., [2017] who found that the release profile of salbutamol sulphate from niosomes followed Higuchi model. This kinetic pattern indicated that the drug release was dominated by diffusion model which normally depended on drug concentration gradient between nano-vesicles and dissolution media with penetration of this media through a porous wall which accompanied by matrix disruption [21]. 


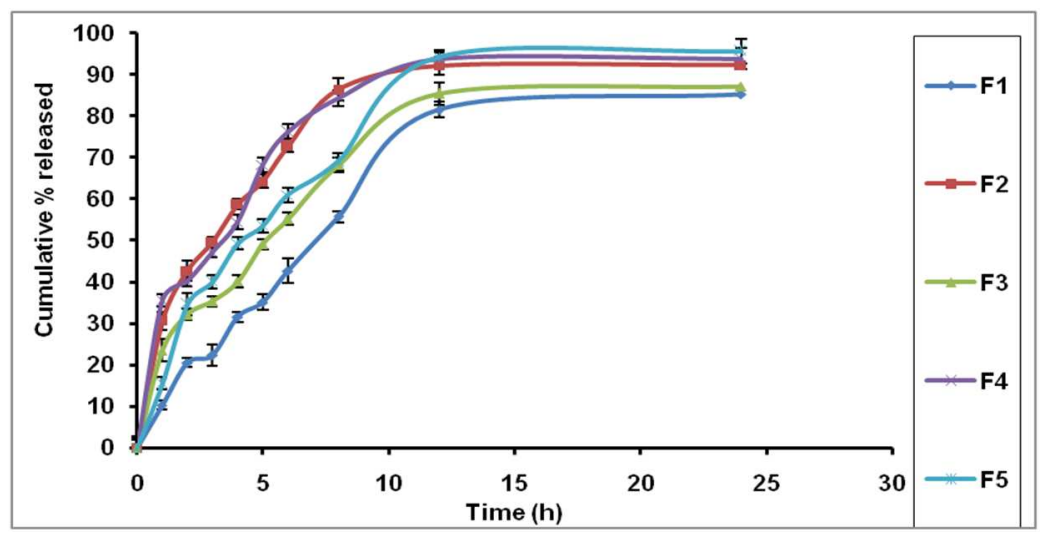

Fig. 3: In vitro release of itraconazoleniosome (F1-F5), data's are expressed as mean $\pm S D(n=3)$

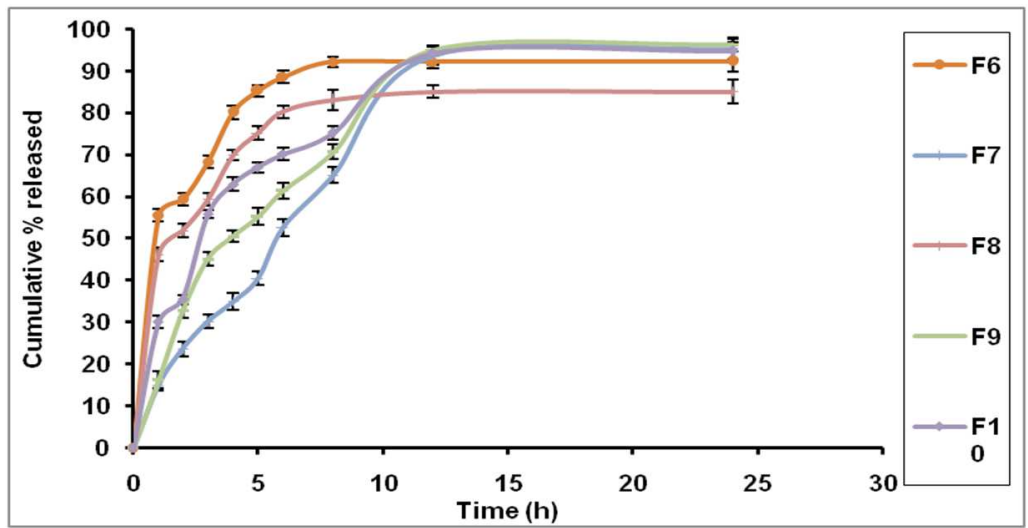

Fig. 4: In vitro release of itraconazole noisome (F6-F10), data's are expressed as mean $\pm S D(n=3)$

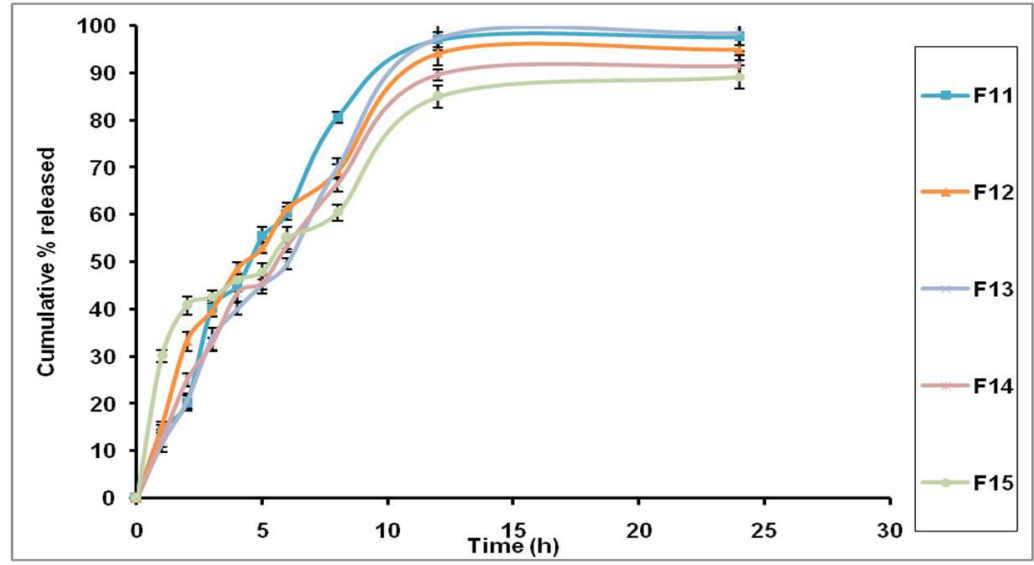

Fig. 5: In vitro release of itraconazole niosome (F11-F15), data's are expressed as mean \pm SD $(n=3)$

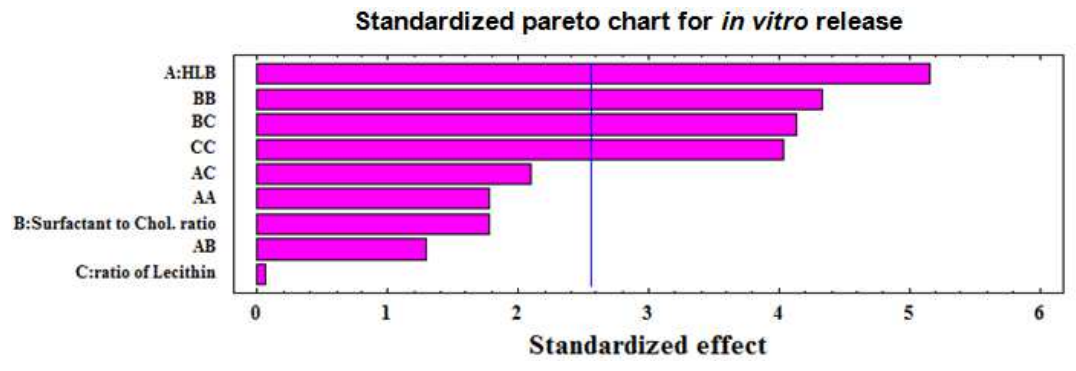

Fig. 6: [A] Standardized Pareto chart for in vitro release of itraconazole 


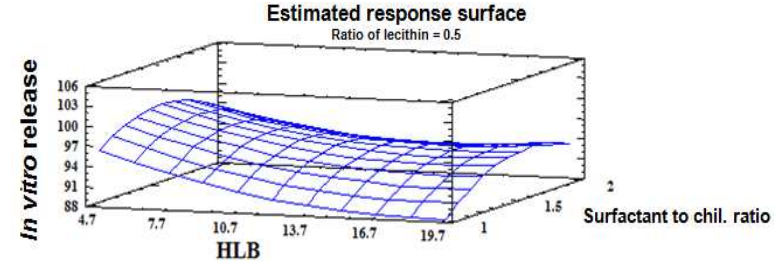

Fig. 6: [B] Three-dimensional contour plot for the effect of $X_{1}$ and $X_{2}$ on in vitro release of itraconazole

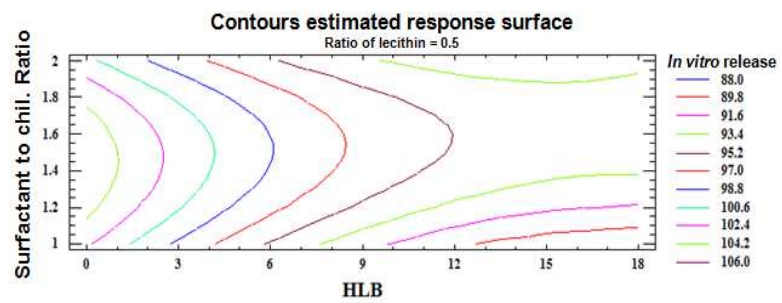

Fig. 6: [C] Two-dimensional contour plot for the effect of $X_{1}$ and $\mathrm{X}_{2}$ on in vitro release of itraconazole

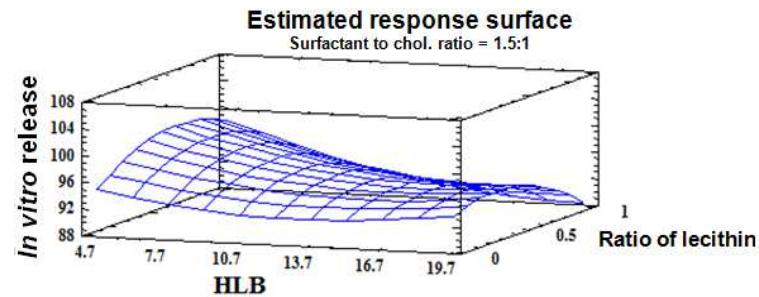

Fig. 6: [D] Three-dimensional contour plot for the effect of $X_{1}$ and $X_{3}$ on in vitro release of itraconazole

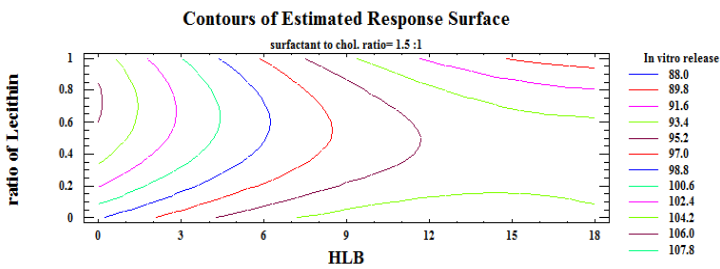

Fig. 6: [E] Two-dimensional contour plot for the effect of $X_{1}$ and $\mathrm{X}_{3}$ on in vitro release of itraconazole

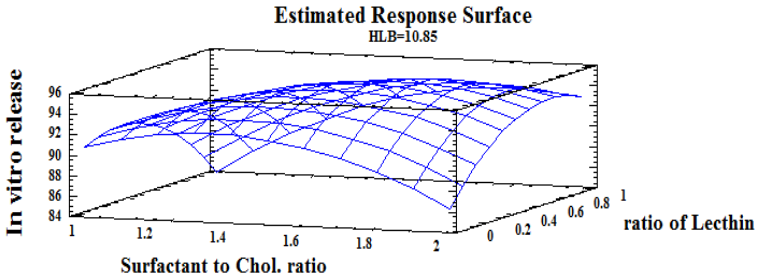

Fig. 6: [F] Three-dimensional contour plot for the effect of $X_{2}$ and $X_{3}$ on in to release of itraconazole

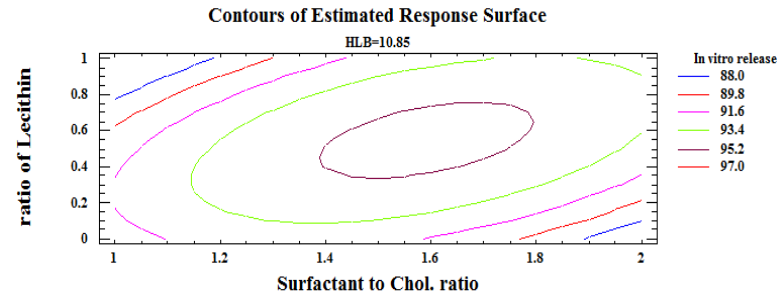

Fig. 6: [G] Two-dimensional contour plot for the effect of $X_{2}$ and $\mathrm{X}_{3}$ on in vitro release of itraconazole

Table 3: The calculated correlation coefficients for the in vitro release of itraconazole pronoisomes employing different kinetic orders or systems

\begin{tabular}{llll}
\hline Formula no. & Correlation coefficient (r) & & Diffusion \\
\cline { 2 - 4 } & Zero & First & 0.959002 \\
F1 & 0.904301 & -0.9386 & 0.904464 \\
F2 & 0.799789 & -0.87456 & 0.947736 \\
F3 & 0.879075 & -0.92175 & 0.904602 \\
F4 & 0.807341 & -0.88858 & 0.947083 \\
F5 & 0.867504 & -0.9301 & 0.807225 \\
F6 & 0.674383 & -0.74769 & 0.951535 \\
F7 & 0.89308 & -0.9282 & 0.836356 \\
F8 & 0.708502 & -0.76919 & 0.945036 \\
F9 & 0.862389 & -0.93302 & 0.9176623 \\
F10 & 0.821331 & -0.91377 & 0.928696 \\
F11 & 0.839682 & -0.92118 & 0.945363 \\
F12 & 0.864263 & -0.92011 & 0.949866 \\
F13 & 0.882462 & -0.93021 & 0.950812 \\
F14 & 0.875488 & -0.92938 & 0.962218 \\
\hline
\end{tabular}

\section{Vesicle size analysis}

The results revealed that all the prepared hydrated proniosomes showed a considerable small vesicle size. The mean vesicle size of hydrated proniosome dispersions ranged from $286.6 \pm(0.588) \mathrm{nm}$ (F10) to $697.5 \pm(0.834) \mathrm{nm}$ (F4). The polydispersity index, PDI which is the measure of particle homogeneity and it varies from 0.0 to 1.0. PDI of itraconazole proniosomes formulations ranged from 0.334 to 0.819 . These low values contributed to relatively narrow size distribution and homogenous distribution [25].

Fig. (8: A-H) showed the effect of the different independent variables on vesicle size of itraconazole proniosomes. By increasing $\left(\mathrm{X}_{1}\right)$; the vesicle size increased due to the direct proportionality did exist between the vesicle size and both chain length and degree of hydrophilicity of the surfactants forming the vesicle bilayer [26]. While increasing $\left(\mathrm{X}_{2}\right)$ resulted in firstly decreasing vesicle size then increased. The decrease in the size firstly was because of a decrease in cholesterol content relative to a surfactant which contributed to increase the hydrophobicity then further increase in surfactant/lipid ratio led to an increase in vesicle size which was substantiated by the increase in the overall degree of hydrophilicity [27]. Also, increasing lecithin content $\left(\mathrm{X}_{3}\right)$ led to increase in mean vesicle size because of the long hydrocarbon chain of lecithin molecules (18C) [15]. 
The same results were recorded by Ashmoony et al., [2014] who observed the nano-size range of Clomipramine niosomes. Also, by analysis of particle size results, they found as the concentration of cholesterol was increased, the particle size of different formulations also increased, which was may be due to the formation of rigid bilayer structure [28].

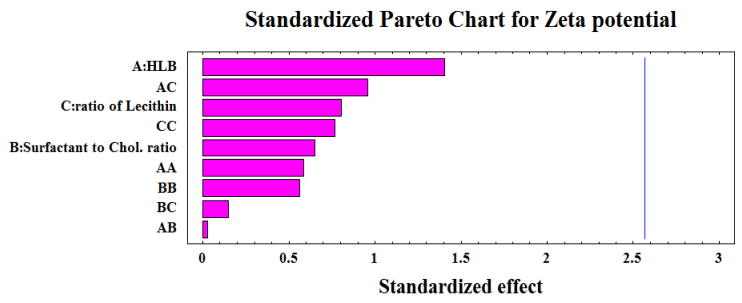

Fig. 7: [A] Standardized Pareto chart for zeta potential of itraconazole proniosomes

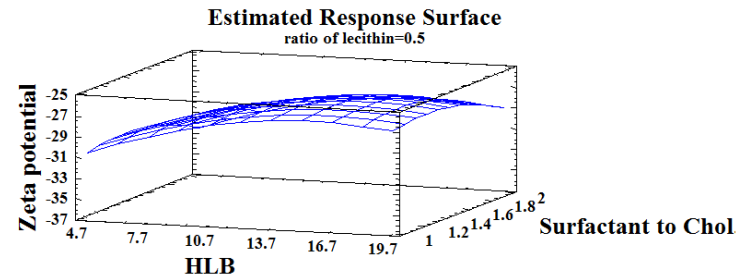

Fig. 7: [B] Three-dimensional contour plot for the effect of $X_{1}$ and $X_{2}$ on zeta potential of itraconazole proniosomes

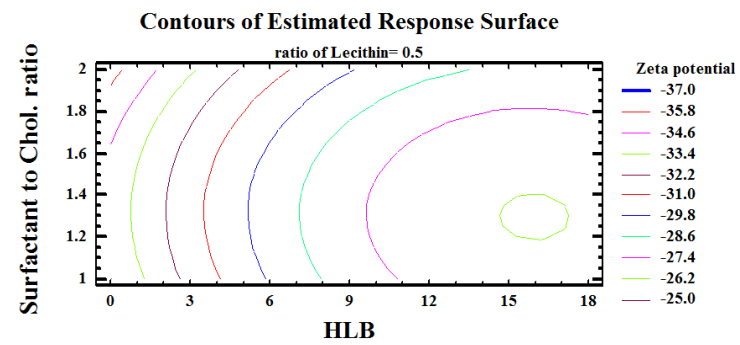

Fig. 7: [C] Two-dimensional contour plot for the effect of $X_{1}$ and $X_{2}$ on the zeta potential of itraconazole proniosomes

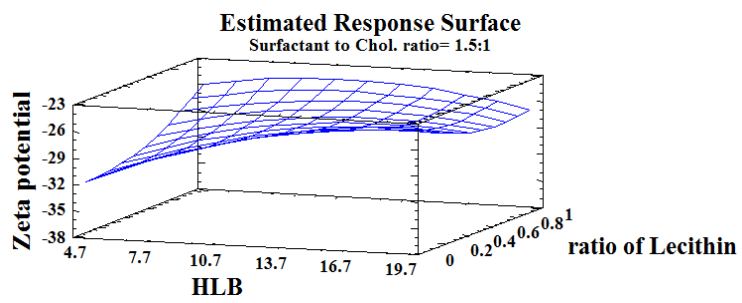

Fig. 7: [D] Three-dimensional contour plot for the effect of $X_{1}$ and $X_{3}$ on zeta potential of itraconazole proniosomes

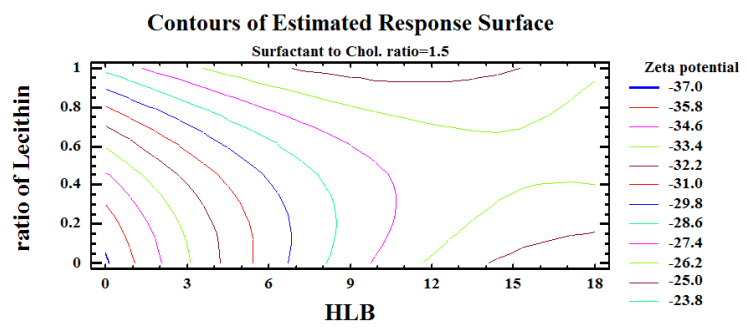

Fig. 7: [E] Two-dimensional contour plot for the effect of $X_{1}$ and $X_{3}$ on the zeta potential of itraconazole proniosomes

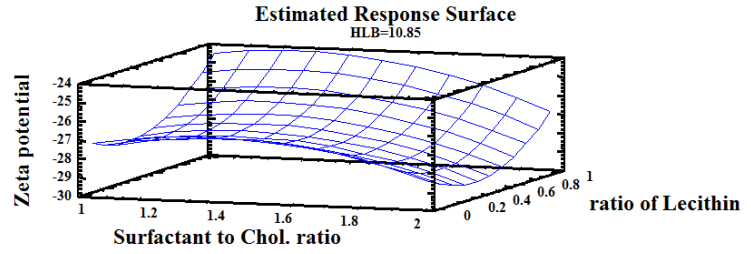

Fig. 7: [F] Two-dimensional contour plot for the effect of $X_{2}$ and $X_{3}$ on the zeta potential of itraconazole proniosomes

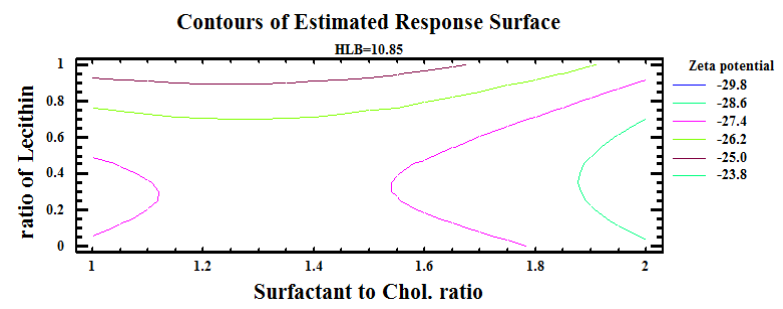

Fig. 7: [G] Three-dimensional contour plot for the effect of $X_{1}$ and $X_{3}$ on zeta potential of itraconazole proniosomes

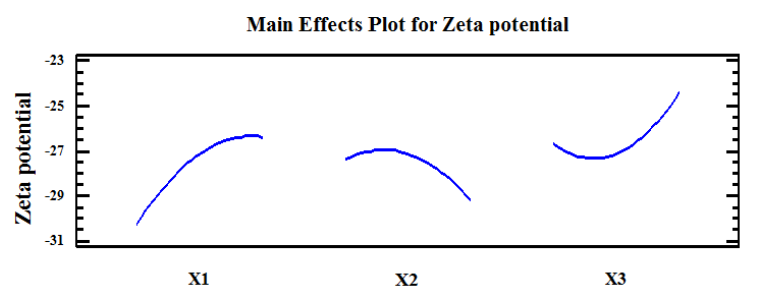

Fig. 7: [H] Main effect plot showing the effect of $X_{1}, X_{2}$ and $X_{3}$ on $\mathbf{Y}_{3}$

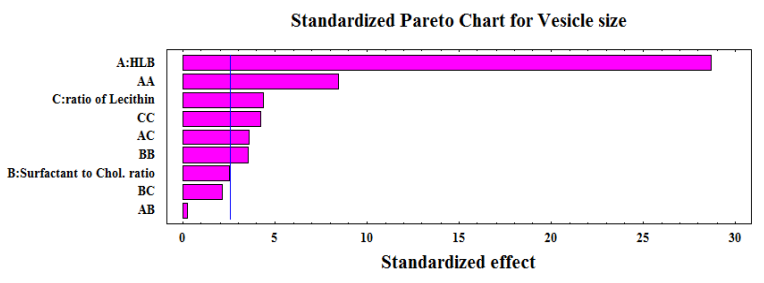

Fig. 8: [A] Standardized Pareto chart for vesicle size of itraconazole proniosomes

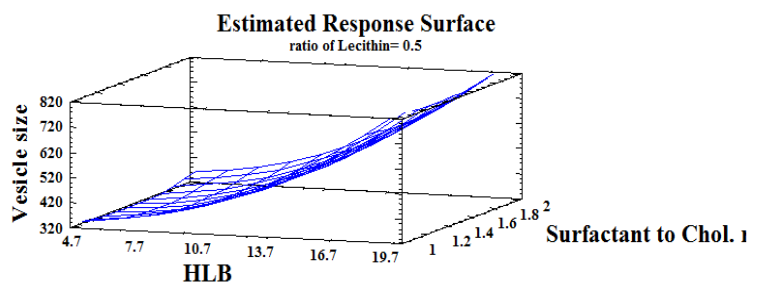

Fig. 8: [B] Three-dimensional contour plot for the effect of $X_{1}$ and $X_{2}$ on vesicle size of itraconazole proniosomes

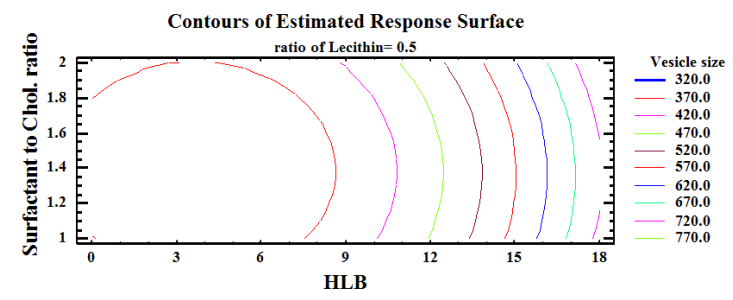

Fig. 8: [C] Two-dimensional contour plot for the effect of $X_{1}$ and $\mathrm{X}_{2}$ on vesicle size of itraconazole proniosomes 


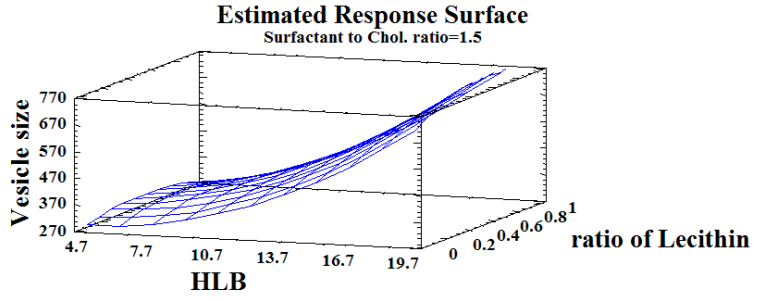

Fig. 8: [D] Three-dimensional contour plot for the effect of $X_{1}$ and $X_{3}$ on vesicle size of itraconazole proniosomes

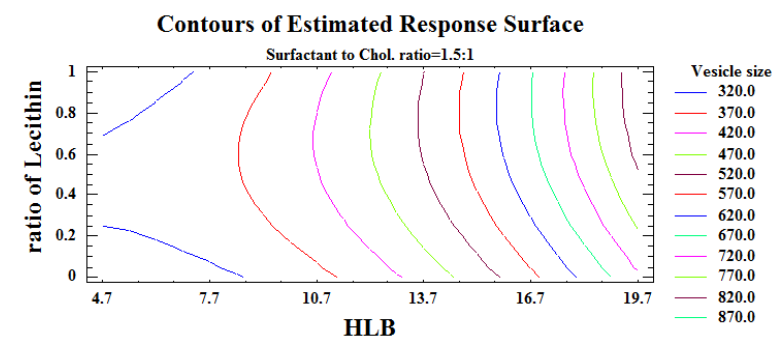

Fig. 8: [E] Two-dimensional contour plot for the effect of $X_{1}$ and $X_{3}$ on vesicle size of itraconazole proniosomes

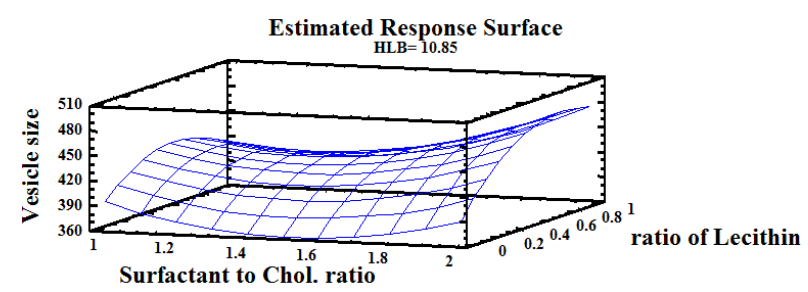

Fig. 8: [F] Three-dimensional contour plot for the effect of $X_{2}$ and $X_{3}$ on vesicle size of itraconazole proniosomes

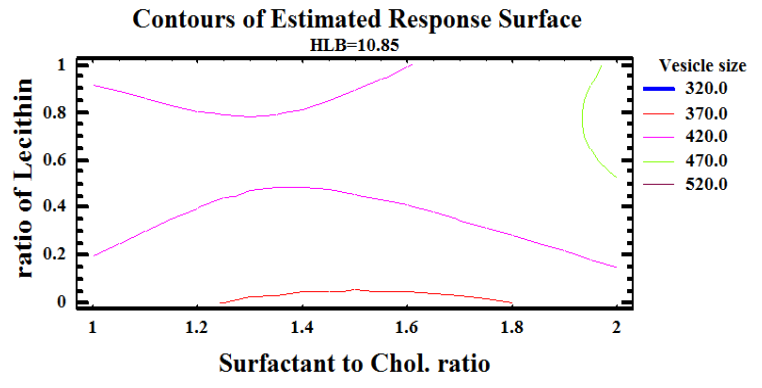

Fig. 8: [G] Two-dimensional contour plot for the effect of $X_{2}$ and $X_{3}$ on vesicle size of itraconazole proniosomes

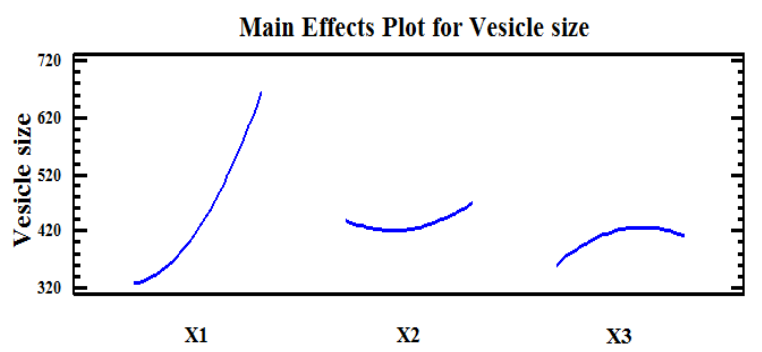

Fig. 8: [H] Main effect plot showing the effect of $X_{1}, X_{2}$ and $X_{3}$ on $Y_{4}$

\section{Statistical analysis}

Tables (4-7) explained the one-way analysis of variance (ANOVA), which partitions the variability in $Y_{1}, Y_{2}, Y_{3}$ and $Y_{4}$ into separate pieces for each of the effects. Then, it tests the statistical significance of each effect through comparing the mean square against an estimate of the experimental error. The effects of all the tested independent variables have a P-values less than 0.05 , indicating that they are significantly different from zero at $95 \%$ confidence level.

Table 4: Analysis of variance for entrapment efficiency $\left(\mathrm{Y}_{1}\right)$

\begin{tabular}{lllll}
\hline Source & Sum of squares & DF & Mean square & F-Ratio \\
\hline A: $\left(X_{1}\right)$ & 160.384 & 1 & 160.384 & 8.97 \\
B: $\left(X_{2}\right)$ & 59.9513 & 1 & 59.9513 & 3.35 \\
C: $\left(X_{3}\right)$ & 32.08 & 1 & 32.08 & 0.0303 \\
AA & 0.08169 & 1 & 0.08169 & 0.1266 \\
AB & 2.7722 & 1 & 2.772 & 0.2381 \\
AC & 0.00002 & 1 & 0.00002 & 0.9487 \\
BB & 0.01066 & 1 & 0.01066 & 0.16 \\
BC & 0.4970 & 1 & 0.4970 & 0.00 \\
CC & 32.1051 & 1 & 32.1051 & 0.00 \\
Total error & 89.4006 & 5 & 17.8801 & 0.03 \\
Total (correlation) & 377.318 & 14 & & 0.9715 \\
\hline
\end{tabular}

R-squared (76.3063) \%; R-squared (adjusted for DF) (33.6576) \%; Standard Error of Est.(4.2284); Mean absolute error (2.02); Durbin-Watson statistic (1.62882).

Table 5: Analysis of variance for in vitro release of itraconazole after $24 \mathrm{~h}\left(\mathrm{Y}_{2}\right)$

\begin{tabular}{|c|c|c|c|c|c|}
\hline Source & Sum of squares & DF & Mean square & F-Ratio & P-Value \\
\hline $\mathrm{A}:\left(\mathrm{X}_{1}\right)$ & 70.9836 & 1 & 70.9836 & 26.54 & 0.0036 \\
\hline $\mathrm{B}:\left(\mathrm{X}_{2}\right)$ & 8.3232 & 1 & 8.3232 & 3.11 & 0.1380 \\
\hline C: $\left(\mathrm{X}_{3}\right)$ & 0.0105 & 1 & 0.01051 & 0.00 & 0.9524 \\
\hline $\mathrm{AA}$ & 8.3863 & 1 & 8.38634 & 3.14 & 0.1368 \\
\hline $\mathrm{AB}$ & 4.4521 & 1 & 4.4521 & 1.66 & 0.2534 \\
\hline AC & 11.7306 & 1 & 11.7306 & 4.39 & 0.0904 \\
\hline $\mathrm{BB}$ & 50.014 & 1 & 50.014 & 18.70 & 0.0075 \\
\hline $\mathrm{BC}$ & 45.5625 & 1 & 45.5625 & 17.04 & 0.0091 \\
\hline $\mathrm{CC}$ & 43.3869 & 1 & 43.3869 & 16.22 & 0.0100 \\
\hline Total error & 13.3717 & 5 & 2.67434 & & \\
\hline Total (correlation) & 256.337 & 14 & & & \\
\hline
\end{tabular}

R-squared (94.7836) \%; R-squared (adjusted for DF) (85.394) \%; Standard Error of Est. (1.63534); Mean absolute error (0.793222); DurbinWatson statistic (2.33819). 
Table 6: Analysis of variance for zeta potential $\left(\mathrm{Y}_{3}\right)$

\begin{tabular}{lllll}
\hline Source & Sum of squares & DF & Mean square & F-Ratio \\
\hline A: $\left(X_{1}\right)$ & 30.381 & 1 & 30.381 & 1.98 \\
B: $\left(X_{2}\right)$ & 6.53411 & 1 & 6.53411 & 0.43 \\
C: $\left(X_{3}\right)$ & 10.0352 & 1 & 10.0352 & 0.2187 \\
AA & 5.247 & 1 & 5.247 & 0.5431 \\
AB & 0.011025 & 1 & 0.011025 & 0.4557 \\
AC & 14.0625 & 1 & 14.0625 & 0.58 \\
BB & 4.90079 & 1 & 4.90079 & 0.00 \\
BC & 0.3481 & 1 & 0.3481 & 0.92 \\
CC & 9.106 & 1 & 9.106 & 0.32 \\
Total error & 76.8276 & 5 & 15.3655 & 0.02 \\
Total (correlation) & 158.898 & 14 & & 0.59 \\
\hline
\end{tabular}

R-squared (51.6498) \%; R-squared (adjusted for DF) (0) \%; Standard Error of Est. (3.91989); Mean absolute error (1.92244); Durbin-Watson statistic (1.68279).

Table 7: Analysis of variance for vesicle size $\left(\mathbf{Y}_{4}\right)$

\begin{tabular}{lllll}
\hline Source & Sum of squares & DF & Mean square & F-Ratio \\
\hline A: $\left(X_{1}\right)$ & 227948.0 & 1 & 227948.0 & 823.48 \\
B: $\left(X_{2}\right)$ & 1794.01 & 1 & 1794.01 & 0.0000 \\
C: $\left(X_{3}\right)$ & 5222.42 & 1 & 5222.42 & 0.0515 \\
AA & 19728.0 & 1 & 19728.0 & 18.87 \\
AB & 13.3225 & 1 & 13.3225 & 71.27 \\
AC & 3642.12 & 1 & 3642.12 & 0.0074 \\
BB & 3558.81 & 1 & 3558.81 & 12.16 \\
BC & 1235.52 & 1 & 1235.52 & 0.0004 \\
CC & 4933.69 & 1 & 4933.69 & 0.0151 \\
Total error & 13.84 .06 & 5 & 276.811 & 0.0158 \\
Total (correlation) & 270593.0 & 14 & & 0.0883 \\
\end{tabular}

R-squared (99.4885) \%; R-squared (adjusted for DF) (98.5678) \%; Standard Error of Est. (16.6376); Mean absolute error (8.13556); DurbinWatson statistic (1.36368).

\section{Optimization of the formulation ingredients}

The dependent and independent variables were related using mathematical relationships. The polynomial equations obtained were;

$\mathrm{Y}_{1}=78.4396-0.27015 \mathrm{X}_{1}+9.7624 \mathrm{X}_{2}+17.9062 \mathrm{X}_{3}-0.00393\left(\mathrm{X}_{1}\right)^{2-}$ $0.2707 \mathrm{X}_{1} \mathrm{X}_{2}+0.00081 \mathrm{X}_{1} \mathrm{X}_{3}-0.215\left(\mathrm{X}_{2}\right)^{2}-1.41 \mathrm{X}_{2} \mathrm{X}_{3}-11.795\left(\mathrm{X}_{3}\right)^{2}$

$\mathrm{Y}_{2}=78.5689-1.58519 \mathrm{X}_{1}+35.7325 \mathrm{X}_{2}+0.4233 \mathrm{X}_{3}+0.03984\left(\mathrm{X}_{1}\right)^{2}+$ $0.3430 \mathrm{X}_{1} \mathrm{X}_{2}-0.5569 \mathrm{X}_{1} \mathrm{X}_{3}-14.721\left(\mathrm{X}_{2}\right)^{2}-13.5 \mathrm{X}_{2} \mathrm{X}_{3}-13.711\left(\mathrm{X}_{3}\right)^{2}$

$Y_{3}=-45.99596+1.33129 X_{1}+12.7927 X_{2}+4.34419 X_{3}-0.0315\left(X_{1}\right)^{2}-$ $0.01707 \mathrm{X}_{1} \mathrm{X}_{2}-0.6097 \mathrm{X}_{1} \mathrm{X}_{3}-4.608\left(\mathrm{X}_{2}\right)^{2}-1.18 \mathrm{X}_{2} \mathrm{X}_{3}+6.2816\left(\mathrm{X}_{3}\right)^{2}$

$\mathrm{Y}_{4}=640.145-20.2871 \mathrm{X}_{1}-384.189 \mathrm{X}_{2}-14.6045 \mathrm{X}_{3}+1.9326\left(\mathrm{X}_{1}\right)^{2}+$ $0.59349 \mathrm{X}_{1} \mathrm{X}_{2}+9.8130 \mathrm{X}_{1} \mathrm{X}_{3}+124.183\left(\mathrm{X}_{2}\right)^{2}+70.3 \mathrm{X}_{2} \mathrm{X}_{3}-146.217\left(\mathrm{X}_{3}\right)^{2}$

The equation represents the effect of process variables $\left(X_{1}, X_{2}\right.$ and $\left.X_{3}\right)$ on the responses $\left(Y_{1}, Y_{2}, Y_{3}\right.$ and $\left.Y_{4}\right)$. Here, variables $X_{2}, X_{3}$ and $\mathrm{X}_{1} \mathrm{X}_{3}$ have positive effects on entrapment efficiency as revealed by the positive value of coefficients in the equation, it means that as the ratio of surfactant to cholesterol $\left(\mathrm{X}_{2}\right)$ and a ratio of lecithin $\left(\mathrm{X}_{3}\right)$ increases, entrapment efficiency increases. Whereas $\mathrm{X}_{1},\left(\mathrm{X}_{1}\right)^{2}, \mathrm{X}_{1} \mathrm{X}_{2}$,
$\left(\mathrm{X}_{2}\right)^{2}, \mathrm{X}_{2} \mathrm{X}_{3}$ and $\left(\mathrm{X}_{3}\right)^{2}$ have negative effects on entrapment efficiency as revealed by negative values of the coefficient in equation 1 , it means that as HLB $\left(\mathrm{X}_{1}\right)$ increases, entrapment efficiency decreases.

Variables $\mathrm{X}_{2}, \mathrm{X}_{3},\left(\mathrm{X}_{1}\right)^{2}$ and $\mathrm{X}_{1} \mathrm{X}_{2}$ have positive effects on in vitro release as revealed by the positive value of coefficients in the equation. While $\mathrm{X}_{1}, \mathrm{X}_{1} \mathrm{X}_{3},\left(\mathrm{X}_{2}\right)^{2}, \mathrm{X}_{2} \mathrm{X}_{3}$ and $\left(\mathrm{X}_{3}\right)^{2}$ have negative effects on in vitro release as revealed by negative values of the coefficient in equation 2. Also, variables $\mathrm{X} 1, \mathrm{X} 2, \mathrm{X} 3$ and $\left(\mathrm{X}_{3}\right)^{2}$ with positive effects on zeta potential assigned by positive value of coefficients in the equation, but $\left(\mathrm{X}_{1}\right)^{2}, \mathrm{X}_{1} \mathrm{X}_{2}, \mathrm{X}_{1} \mathrm{X}_{3},\left(\mathrm{X}_{2}\right)^{2}$ and $\mathrm{X}_{2} \mathrm{X}_{3}$ have negative effects on zeta potential assigned by negative values of coefficient in equation 3. In addition to variables $\left(\mathrm{X}_{1}\right)^{2}, \mathrm{X}_{1} \mathrm{X}_{3},\left(\mathrm{X}_{2}\right)^{2}$ and $\mathrm{X}_{2} \mathrm{X}_{3}$ have positive effects on vesicle size as revealed by the positive value of coefficients in the equation. While, $\mathrm{X}_{1}, \mathrm{X}_{2}, \mathrm{X}_{3}, \mathrm{X}_{1} \mathrm{X}_{2}$ and $\left(\mathrm{X}_{3}\right)^{2}$ have negative effects on vesicle size as revealed by negative values of the coefficients in equation 4.

These variables were optimized with a fifteen run box behnken design as shown in table (8), when mixing of $\mathrm{X}_{1}$ (4.7), $\mathrm{X}_{2}$ (1.721) and $\mathrm{X}_{3}$ (0.389), predicted optimum response for entrapment efficiency $(95.46 \%)$, for $Y_{2}(98.5 \%)$, for $Y_{3}(-31.44 \mathrm{mV})$, and for $Y_{4}(343.197 \mathrm{~nm})$.

Table 8: Optimum desirability

\begin{tabular}{|c|c|c|c|}
\hline Independent variables & Low & High & Optimum \\
\hline $\mathrm{X}_{1}=\mathrm{HLB}$ & 4.7 & 17 & 4.7 \\
\hline $\mathrm{X}_{2}=$ Surfactant-Cholesterol ratio & $1: 1$ & $2: 1$ & 1.721 \\
\hline $\mathrm{X}_{3}=$ ratio of Lecithin & 0 & 1 & 0.389 \\
\hline Response & \multicolumn{3}{|c|}{ Optimum } \\
\hline $\mathrm{Y}_{1}$ & \multicolumn{3}{|c|}{$95.46 \%$} \\
\hline $\mathrm{Y}_{2}$ & \multicolumn{3}{|c|}{$98.5 \%$} \\
\hline $\mathrm{Y}_{3}$ & \multicolumn{3}{|c|}{$-31.44 \mathrm{mV}$} \\
\hline $\mathrm{Y}_{4}$ & \multicolumn{3}{|c|}{$343.19 \mathrm{~nm}$} \\
\hline
\end{tabular}




\section{Formulation of the optimized formula}

The optimized formula was prepared by the slurry method. $Y_{1}$ of the optimized formula was found to be $94.95 \% \pm 0.36$, while $Y_{2}$ was $98.13 \pm 2.51 \%, Y_{3}$ was $-30.15 \pm 0.41 \mathrm{mV}$ and $\mathrm{Y}_{4}$ was $340.48 \pm 0.581 \mathrm{~nm}$. The Kinetic models of the optimized formula were found to obey Higuchi's diffusion model.

Table (9) showed the actual and predicted effect of the optimized variables on different responses. Small residual values indicated that there was no great difference between actual and predicted values.

Scanning electron micrographs showed the formation of proniosomes loaded on a mannitol carrier before hydration of the proniosomes and their shape were almost spherical as shown in fig. (9). Our results were in good agreement with Arafa et al., [2017] who observed salbutamol sulphate under scanning electron microscope and found spherical niosomes with some discontinuities in the membrane. This was due to the acyl-chain structure of span 60 , which could affect cholesterol interactions causing variations in cholesterol distribution. The polar head group of non-ionic surfactant must cover the non-polar portion of cholesterol; this coverage is essential to avoid the unfavourable free energy of cholesterol that when contacts with water decrease the repulsion between cholesterol molecules [21].

Transmission electron micrographs revealed the formation of well identified hydrated niosomal vesicles as shown in fig. (10). The examined niosomes appeared as spherical, nano-sized, unilamellar vesicles with sharp boundaries and well separated from each other [29]. This could be attributed to the fact that, on niosome formation using span, spherical shaped niosomes were obtained in order to minimize the surface free energy. The non-ionic surfactants form a closed bilayer vesicle in aqueous media based on its amphiphilic nature using some energy [30].

Table 9: Actual, predicted and residual values for itraconazole proniosomes optimized formula

\begin{tabular}{llll}
\hline Response & Actual values & Predicted values & Residual \\
\hline$Y_{1}$ & $94.95 \pm 0.36 \%$ & $95.46 \%$ & -0.51 \\
$Y_{2}$ & $98.13 \pm 2.51 \%$ & $98.5 \%$ & -0.37 \\
$Y_{3}$ & $-30.15 \pm 0.41 \mathrm{mV}$ & $-31.44 \mathrm{mV}$ & -1.29 \\
$\mathrm{Y}_{4}$ & $340.48 \pm 0.581 \mathrm{~nm}$ & $343.19 \mathrm{~nm}$ & -2.71 \\
\hline
\end{tabular}

Data's are expressed as mean $\pm \operatorname{SD}(n=3)$

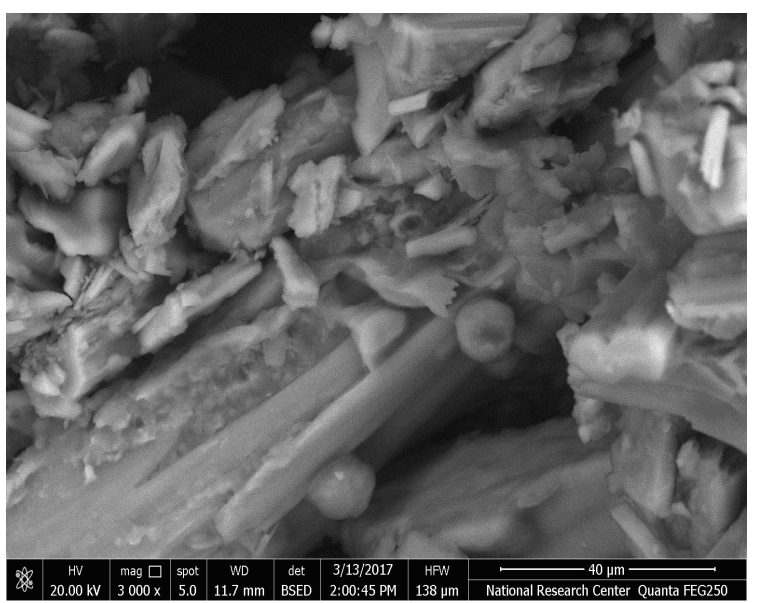

Fig. 9: Scanning electron microscope of the optimized formula of itraconazole proniosomes

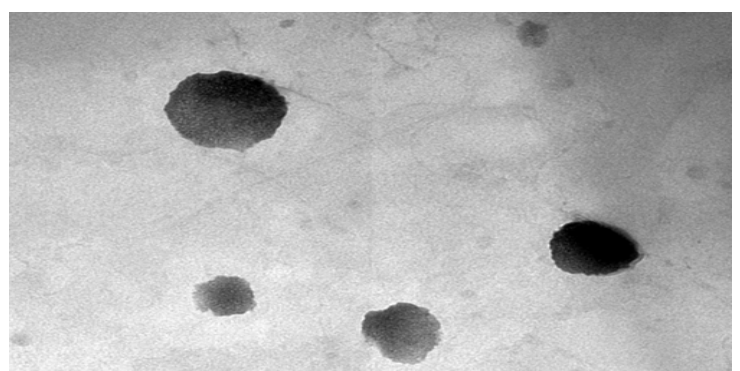

Fig. 10: Transmission electron microscope of the optimized formula of itraconazole proniosomes

\section{CONCLUSION}

In the present work, itraconazole proniosomes were prepared by the slurry method. Box behnken design was successfully applied to optimize the effect of HLB, a surfactant to cholesterol ratio and the ratio of lecithin on entrapment efficiency, in vitro release, zeta potential and vesicle size. The derived polynomial equations and main effect values aid in predicting the values of selected independent variables as 4.7 from $\mathrm{X}_{1}, 1.721$ from $\mathrm{X}_{2}$ and 0.389 from $\mathrm{X}_{3}$ for preparation of optimum itraconazole formulation with desired properties, as entrapment efficiency $\left(\mathrm{Y}_{1}\right)$ of $94.95 \%$, in vitro release $\left(\mathrm{Y}_{2}\right)$ of $98.13 \%$, zeta potential $\left(\mathrm{Y}_{3}\right)$ of- $30.15 \mathrm{mV}$ and vesicle size $\left(\mathrm{Y}_{4}\right)$ of $340.48 \mathrm{~nm}$ and these observed values of the optimized formula were close to the predicted values.

\section{AUTHORS CONTRIBUTIONS}

All the author have contributed equally

\section{CONFLICT OF INTERESTS}

Declared none

\section{REFERENCES}

1. Cheriyan P, George BJ, Thomas N, Raj P, Samuel J, Carla SrB. Formulation and characterization of maltodextrin based proniosomes of cephalosporins. World J Pharm Sci 2015;3:62-74.

2. El-Ridy MS, Bawai AA, Safar MM, Mohsen AM. Niosomes as a novel pharmaceutical formulation encapsulating the hepatoprotective drug silymarin. Int J Pharm Pharm Sci 2012;4:549-59.

3. Naggar VF, Elgamal SS, Allam AN. Proniosomes as a stable carrier for oral acyclovir: Formulation and physicochemical characterization. J Am Sci 2012;8:417-28.

4. Sammour OA. Improvement of encapsulation efficiency of timolol maleate in liposome by the freeze-thawing method. Zag J Pharm Sci 1992;1:34-42.

5. Tang J, Wei H, Liu H, Ji H, Dong D, Zhu D, et al. Pharmacokinetics and biodistribution of itraconazole in rats and mice following intravenous administration in a novel liposome formulation. Drug Delivery 2010;17:223-30.

6. Gareth A. Encyclopedia of pharmaceutical technology. $2^{\text {nd }}$ ed. Marcel Dekker [NY]; 2002.

7. Tank CJ, Bokhataria C, Baria AH. Formulation and evaluation of aceclofenac loadedmaltodextrin based proniosomes. Int J ChemTech Res 2009;1:567-73.

8. Sampathi S, Mankala SK, Wankar J, Dodoala. Nanoemulsion based hydrogels of itraconazole for transdermal drug delivery. J Sci Ind Res 2015;74:88-92.

9. Asija R, Sharma D, Nirmal H. Development of proniosomal gel as a drug carrier for transdermal delivery of acyclovir. J Drug Discovery Ther 2014;2:41-51. 
10. Thomas L, Viswanad V. Formulation and optimization of the clotrimazole-loaded proniosomal gel using $3^{2}$ factorial design. Sci Pharm 2012;80:731-48.

11. Box GE, Hunter WG, Hunter JS. Statistics for experiments: design with more than one blocking variable. $2^{\text {nd }}$ ed. [NY]: Wiley Publisher; 1978.

12. Uchegbu IF, Florence AT. Non-ionic surfactant vesicles (niosomes) physical and pharmaceutical chemistry. Adv Colloid Interface Sci 1995;58:1-55.

13. Badawi A, El Nabarawi MA, Elrehem RT, Fayed BA. Formulation and evaluation of dispersed permethrinproniosomes in powder and microemulsion-based hydrogel bases for the treatment of scabies. Int J Pharm Pharm Sci 2016;8:221-9.

14. Alsarra IA. Evaluation of proniosomes as an alternative strategy to optimizepiroxicam transdermal delivery. J Microencapsulation 2008;1:1-7.

15. Benipal G. Design development and evaluation of proniosomal gel of an antifungal drug ketoconazole. Int J Pharm Sci Rev Res 2015;31:265-72.

16. Acharya A, Kumar KGB, Ahmed MG, Paudel S. A novel approach to increase the bioavailability of candesartan cilexetil by proniosomal gel formulation: in vitro and in vivo evaluation. Int J Pharm Pharm Sci 2016;8:241-6.

17. Pardakhty A, Varshosaz J, Rouholamini A. In vitro study of polyoxyethylene alkyl ether niosomes for delivery of insulin. Int J Pharm 2007;328:130-41.

18. Abdelbary GA, Amin MM, Zakaria MY. Ocular ketoconazoleloaded proniosomal gels: formulation, ex vivo corneal permeation and in vivo studies. Drug Delivery 2017;24:309-19.

19. Kumar BS, Krishna R, Lakshmi PS, Vasudev DT, Nair SC. Formulation and evaluation of niosomal suspension of cefixime. Asian J Pharm Clin Res 2017;10:194-201.
20. Pankaj S, Rini T, Dandagi PM. Formulation and evaluation of proniosome based drug delivery system of the antifungal drug clotrimazole. Int J Pharm Sci Nanotech 2013;6:1945-51.

21. Arafa MG, Ayoub BM. Nano-vesicles of salbutamol sulphate in metered dose inhalers: formulation, characterization and in vitro evaluation. Int J Appl Pharm 2017;9:100-5.

22. Singla S, Harikumar SL, Aggarwal G. Proniosomes for penetration enhancement in transdermal system. Int J Drug Devand Res 2012;4:1-13.

23. Kamboj S, Saini V, Bala S. Formulation and characterization of drug loaded nonionic surfactant vesicles (niosomes) for oral bioavailability enhancement. Sci World J 2014:1-8. http://dx.doi.org/10.1155/2014/959741

24. Okare VC, Attama AA, Ofokansi KC, Esimone CO, Onuigbo EB. Formulation and evaluation of niosomes. Indian J Pharm Sci 2011;73:323-8.

25. Chauhan MK, Sahoo PK, Rawat AS, Dugga LD, Kandwal M, Nidhi S. Formulation, characterization and in vitro evaluation of tactically engineered proniosomes for successful oral delivery of ramipril. Pharm Lett 2015;7:93-7.

26. Balakrishnan P, Shanmugam S, Lee WM, Kim JO, Oh DH, Kim DD, et al. Formulation and in vitro assessment of minoxidilniosomes for enhanced skin delivery. Int J Pharm 2009;10:1004-20.

27. Desai S, Doke A, Disouza J, Athawale R. Development and evaluation of antifungal topical niosomal gel formulation. Int J Pharm Pharm Sci 2011;3:224-31.

28. Ola AMM, El-Ashmoony MM, Elgazayerly ON. Niosomeencapsulated clomipramine for transdermal controlled delivery. Int J Pharm Pharm Sci 2014;6:567-75.

29. Mishra A, Kapoor A, Bhargava. A proniosomal gel as a carrier for transdermal drug delivery of clotrimazole. Int J Pharm Pharm Sci 2012;4 Suppl 4:610-4.

30. Das MK, Palei NN. Sorbitan ester niosomes for topical delivery of rofecoxib. Indian J Exp Biol 2011;49:438-45 